\title{
The Influence of Poverty and Well Being of the Elderly People in Nyanza Province, Kenya
}

\author{
Alice Nyamanga Ondigi \\ Department of Community Resource Management \& Extension \\ P.O Box 43844, Kenyatta University, Nairobi, Kenya \\ E-mail: ondigialice@yahoo.com \\ Samson Rosana Ondigi \\ Department of Educational Communication and Technology \\ P.O Box 43844, Kenyatta University, Nairobi, Kenya \\ E-mail: ondigi@yahoo.com
}

\begin{abstract}
Received: April 14, 2011
Accepted: November 28, 2011 Published: February 1, 2012

doi:10.5539/ass.v8n2p211

URL: http://dx.doi.org/10.5539/ass.v8n2p211
\end{abstract}

\begin{abstract}
Kenya's population aged $60+$ is estimated to be 1.8 million, that is, $9 \%$ of the total population and is projected to increase to about 2.2 million by 2012 . This raises questions as to the socio-economic situation and well-being of the older population given the prevailing economic conditions and decreasing family sizes occasioned by family planning and the migration of the youth to urban areas in search of employment. A descriptive study using quantitative survey questionnaires, qualitative interviews and observation checklist was conducted among a sample of 120 older men and women aged women aged 60+ in three districts in Nyanza province. The majority (57\%) of older people earned incomes of less than Ksh. 2000 (US \$25), older people's major source of income was from small-scale growing and selling of vegetables, eggs, milk, and fruits. The majority of the sample (64\%) had only completed primary education, $68 \%$ had low food nutrient intake, $66.7 \%$ hypertension, $13 \%$ diabetes, $73 \%$ joint aches, 22\% suffered from HIV/AIDS, 29\% were affected by HIV/AIDS, 77.5 of women had menopause related discomforts, and $19.2 \%$ of men had prostate problems. Although $82 \%$ had geographical access to health facilities, services were experienced as unaffordable or inadequate. In conclusion, older people's poverty produces vulnerability to malnutrition and untreated degenerative diseases. Dependence on help from children and well-wishers is older people's main, but inadequate, resource for trying to cope with this vulnerability. Despite formal government commitment, concrete policies to ensure the economic well-being of older people are absent. National level research to establish the nature and determinants of older people's socio-economic situation is needed to promote and inform such policy development.
\end{abstract}

Keywords: Elderly, Poverty, Wellbeing, Nutrition

\section{Background to the study}

Globally, both the number and proportion of older people over 60 years are virtually growing in all nations. An estimated 605 million older persons in the world, and nearly 400 million of who are living in low-income countries were reported in 2002. It is also reported that by 2025 , the number of older persons worldwide is expected to reach more than 1.2 billion, with about 840 million of these in low-income countries (Siegel, 1976)

In conformity with United Nations and African Union definitions, Kenya has adopted the

Definition of older people as those aged 60 years and above although the retirement

age of employment is 55 years. In terms of demographic profiles the number of older persons has not risen dramatically since 1989. The statistics show that about 1.5 million people in Kenya are aged 60 years and above, thus constituting 4.8 percent of the total population. The distribution of older persons varies across the eight provinces. The highest concentration of older persons is in Nyanza and Rift Valley provinces. 
It has been noted that many of the diseases suffered by older persons are as a result of dietary factors, some of which have been having impact since childhood. These dietary changes seem to affect risk-factor levels through life and have even greater impact in older people. Among the aged, vitamin or mineral deficiencies seldom do not develop abruptly, instead they evolve slowly over a period of time as a result of limited intake, impaired absorption, or excessive excretion (Boykin, 1980; Beeuwkes, 1960). Marginal deficiency is characterized by gradual nutrient depletion and personal lack of well being associated with impairment of certain biochemical functions. The level of income and nutritional adequacy are inter-related, for example, Nizel (1976) argues that the nutritional intake of the elderly is influenced by the socio-economic factors that determine the congregated meal program or delivery of the meals to the home, whereas the variability of the diet is influenced by the distribution of the nutrients in particular foods (Ondigi, 2003). The author further argues that adaptation to changes in life-style, health and economic status can bring about changes in eating patterns. It is apparent that increasing age and decreasing calorie requirements result in the consumption of less food and can lead to nutritional inadequacy.

Understanding the socio-economic status of the elderly is important for it indicates their wellbeing in the later years. The elderly who are economically empowered are able to take care of themselves, can hire people to assist them, are able to manage their health affairs and can manage a good diet (Alder, et-al. 1994; Ondigi, 2003). The highly noted incidence of poverty among the poor could be explained by factors such as declining global economic growth where Kenyan's growth is at $0.5 \%$, with gender income disparities of the biggest gap among women in rural areas. The notable lifestyles of the elderly in rural Kenya is greatly influenced by bad governance and corruption which have locked the Kenyan government in the Goldenberg scam of KANU regime and Anglo-Leasing of the NARC government, inefficient delivery of services to the rural areas where infrastructure and inadequate services compound the difficulties experienced by majority of the poor people.

In addition, the HIV/Aids pandemic has both directly and indirectly affected the aged some of who are affected or infected, while some are bewildered by responsibilities of taking care of the orphans - such as providing food, education and the medical cares among other responsibilities. Finally the environmental factors such as prolonged delays of rainfall which affects farming activities that is the main livelihood for the majority of people, whereas the said adverse effects of World Bank structural adjustment programs and the district focus programs in Kenya have affected many people among which include the elderly population. In addition, Although Kenya has prepared a final Draft National Policy on Ageing in line with Madrid International Plan of Action on Ageing (MIPAA) and African Union Framework Guidelines, this report gives a profile on the status and implementation of the National Policy on Ageing. The report reviews the situation of older persons in the country, highlights the progress made in improving their rights since the Vienna and Madrid conferences and gives recommendations on the interventions required. This is yet to yield significant results.

\section{Problem statement}

Aging is a process that affects all human beings throughout the universe. The elderly people continue to strive for their survival, which in most cases leave them malnourished, and in poor health conditions (UNDP 2006, Crimmins \& Ingegneri, 1990; Cicirelli, 1983). This kind of life is at times lonely, stressful and demanding as the elderly have limited support at the time their energies are waning (Boss'e, et-al. 1991). The literature available as indicated by the 9th National Development Plan (2002 - 2008, the Sensational Paper No. 1 of 2000 on National Population Policy Constitutional Review, and the Kenya National Policy on Ageing is not clear on the government's policy regarding the welfare of the elderly in Kenya is implemented. The social welfare of the elderly is left to the family members including children, church organizations or communities whereby it becomes a burden to those that are willing to assist the elderly Therefore, this study seeks to investigate the influence of poverty and the wellbeing of the elderly people in Nyanza province, Kenya.

\section{Objectives of the study}

This study was important in highlighting the plight of the elderly poor, as well as establishing the Kenyan government policy regarding their well-being. The following research objectives were pursued to understand the state of poverty and the well-being of the elderly in Nyanza province, Kenya:

[i] To determine the socio-economic status of the people aged $60+$

[ii] To investigate the nutritional in-take of the elderly,

[iii] To establish the health status of the elderly,

[iv] To establish the coping mechanism of the elderly, and

[v] To investigate the government policy on the elderly status in Kenya. 


\section{Significance of the study}

This study is useful in for the government of Kenya in implementing the policy on welfare of the elderly in Kenya

\section{Methods of study}

This descriptive survey study used both qualitative and quantitative techniques in collecting and analyzing data. Various instruments including questionnaires, interview guide questions and observation checklists were used in collecting data from a sample of 120 elderly men and women aged 60+. The respondents were randomly sampled from three districts (Nyamira, Kisii Central, and Gucha commonly referred to as Gusiiland) in Nyanza province, Kenya. This area was purposefully chosen because it has got diversified groups of the elderly that were being investigated. The researchers employed the snowballing techniques to get the 120 elderly people that were targeted for study. There was no magic in the 120 respondents except the researchers felt it will give a feel of what the study was set to establish.

Thus, the researchers approached the chiefs in three locations in each of the districts and asked them to identify the elderly in their areas of jurisdiction. The assistant chiefs with the help of the village elders assisted in identifying 10 elderly persons in each location who were visited and the identified respondents directed us to their constituent elderly people aged $60+$ years. Those whom the researchers visited and interviewed gave names and directions of other elderly people within the localities. The greatest advantage of snowballing is having the opportunity to learn the respondents from colleagues who know them. The researchers had a chance to interact and make observations of the living conditions, the attitude of the respondents and personal experiences with them. The researchers ensured that the research objectives were achieved.

\section{Reporting the findings}

The findings of the study indicated that among the total population of 120 respondents, $49(40.9 \%)$ were Men and $71(59.2 \%)$ were women. Of the total respondents, $80(66.6 \%)$ were married, and $40(33.4 \%)$ were single, that is, they included the windows and widowers, the unmarried and separated as in Figure1 below:

Age was considered an important variable in this study because the researchers wanted to investigate the age range of elderly people in the rural communities and the respondents' age distribution is as shown in Figure 2 below:

The majority of the respondents, that is, $45.8 \%$ were aged between 60 and 65 years, whereas $6.7 \%$ were over 70 years.

On the level of education of the respondents, $13(1.8 \%)$ had no formal education, $81(67.5 \%)$ had primary education, $17(14.1 \%)$ had secondary education, and $9(7.5 \%)$ had University education. Further, the findings indicated that the social economic status of the respondents in terms of employment showed that the majority (47.5\%) were unemployed, $18 \%$ on contract basis, and $34.1 \%$ self employed as shown in Figure 3 below

The $47.5 \%$ of the respondents who were unemployed, most of them dependent on support from their families, well wishers including neighbors and community organizations such as churches. About $18.5 \%$ were working on contract basis because they had already retired and were earning some pension (national social security fund) from the government, $43.1 \%$ reported to be self employed, that is, were supporting themselve from the income they generated through owned business such as retail shops, matatus, and small scale farming.

Most elderly families in Kenyan are engaged in farming as a common activity for income generating, while pension (NSSF) is the only retirement benefits the retired civil servants receive from the government. The farming activities the elderly people in most Kenyan communities do include: market gardening which is the growing and selling of vegetables, poultry keeping for eggs, Zero-grazing for milk, and growing fruits on small quantities. Most of these communities are poor by all standards given the distribution of their monthly earning as distributed in Figure 4 below:

\subsection{Socio-economic status of the elderly}

The socio-economic status of the elderly is important in trying to understand how the elderly were able to meet their needs and wants on a daily basis. According to the findings of this study, majority of the elderly $79.1 \%$ had an income of less than Kenya Shillings 4000/. This level of income is too low for a family to survive on comfortably. Given that majority of the elderly had completed primary education, their pension or sources of income are limited, and even for those who had secondary or university education were poorly remunerated, hence their pension was very low. When asked how they coped with the prevailing conditions of poverty and the associated many challenges in life; below are some of their responses: 
"My children see me as a burden to them due to my hailing condition. I think it will be a relief for them when I die" (an 85-year-old woman, from Gucha district).

"We had only one son, both him and his wife died from Aids and left us to care for their seven children... wish our government will built homes to care for this children who are left orphans"(a 63 year old woman, Nyamira district).

"While a government cannot put food on the table for me or my family, my expectations have been very high and mixed because of the greediness of political leaders. The government has a duty to provide better services to the citizens and the expectation is that I get better medical services on visiting the health centers, More often, thee are no enough health facilities in the nearby center I attend, such as lack of sanitary facilities like water in the toilets or doctor's examination rooms. The nurses are the ones handling patients even on complicated cases, prescriptions are not in pharmacy and therefore patients are required to buy. Communication to and from hospitals in case of emergency is very poor. Roads are impassable during rain season neither are vehicles available," (a 65 year old man, Kisii district).

When probed further on who they turned to when faced with problems, the majority of the respondents, $80(67 \%)$ indicated that they relied on family members, that is, children, grand-children and relatives; $33(27.5 \%)$ said community members, neighbors and friends assisted while a further 7(5.8\%) got help from some organizations such as NGOs, Community Based Organizations (CBOs), and churches. The respondents were further asked what they did when there was nobody to assist them and table 1 below represents their responses.

The majority engaged in religious matters or socialized with friends with a hope to getting help from the associates and giving up their lives to God for help. The churches were doing a great deal in assisting the elderly in the region. The majority of the respondents verified that they do not get any assistance from the government.

This findings is supported by the study done by UNDESA (2010) which indicates that the majority of older people in Kenya are faced with a host of problems that vary from

economic, health, social and other personal problems.

\subsection{Nutritional in-take}

This study investigated the respondents' nutritional in-take to establish how well the elderly ate and how best their diet was balanced. Good nutritional practices are very important during old age for health development and defense from diseases. This study attempted to investigate whether older people involved in this study ate a balanced diet. A range of foodstuffs was listed in the four food group categories from which they responded. The findings indicated that about $41 \%$ of the respondents ate two or more servings per day from food group A, $30 \%$ from food group B, $76 \%$ from food group C, and 71\% from food group D (See table 6). However, $92 \%$ of the respondents reported that they did not eat anything in food group A, most of them did not eat fish, chicken, and eggs mainly because of poverty and some cultural taboos - a believe which denies women essential nutrients for healthy development as can be seen in table 2 below.

A summary of the food intake showing those who ate two or more servings per day is shown in Figure 5 below:

This means that of the total respondents, only $23 \%$ of the elderly people ate a well balanced diet while the majority $77.5 \%$ ate poorly, hence their health status were compromised by the eating habits. Use of food supplements is necessary where the elderly do not get a balanced diet. This is because food supplements provide all nutrients to the elderly people because it is difficult for them to obtain adequate vitamin and minerals from food alone.

The respondents were asked if they ever used food supplements, and the findings revealed that $13 \%$ used food supplements once a week or less, $14 \%$ used several times a week, and $17 \%$ used it every day as recommended by their doctors, while $56 \%$ did not use it at all which was obvious that the majority of the respondents in this study were not aware of the importance of using food supplements. The few who knew about the food supplements could not afford to buy even when recommended by their health care provider. This findings were supported by United Nations Development report - International Poverty Centre (2006)

\subsection{Health status of the elderly}

It is important to understand the health status of the elderly, as they are highly vulnerable to sickness due to limited health care, poor dietary conditions and hardships. When the respondents were asked if they had ever been hospitalized or obtained medication for the following health related problems, table 3 below outlines their response: 
It is evident from the responses that the majority $80(66.6 \%)$ had High Blood Pressure, while $73(60.8 \%)$ had joint aces due to old age. About $17.5 \%$ of the elderly women indicated they had menopause related discomforts. Studies indicate that this being a natural process nothing could be done at this stage other than putting up with the condition (Bush, et-al, 1994; Cutler and Grams, 1998; Cutler and Garcia, 1993). A further 42(51\%) faced the challenges of caring for the HIV/Aids, affected or infected persons including the orphans.

\section{Discussions of the findings}

\subsection{The Socio-economic status of the elderly}

The majority of the respondents, that is, $79.1 \%$ had incomes of less than Kenya Shillings 4,000/. The sources of livelihood were very limited and their daily commitments were overwhelming. The mechanisms in place such as the poverty reduction framework embraced by the Kenyan government in the past has shown that a number of policies and programs enacted to improve economic growth and reduce poverty including: Sentitional papers, development plans, district focus for rural development, social dimensions of development have achieved very little or otherwise no significance changes in the rural economy. The most hurt therefore are the less fortunate in the society, the poor, the aging and children who have limited resources to survive on.

Further, the recent initiative under implementation, that is, the National Poverty Eradication Plan (NPEP) 1999-2015 and the Millennium Development Goals (MDGs) 2000-2015, the Poverty Reduction Strategy Paper (PRSP) 2001-2010 and Economic Recovery Strategy for Wealth and Employment Creation (ERSWEC) 2003-2007, some instituted during KANU regime and NARC regime have faded in the face of massive corruption such as Golden-berg and Anglo-Leasing scams. The situation witnessed is that of Kenyans anguishing in poverty, despair and claim of want that impacts the poor and aged beyond reason of survival.

The projected reduction of poverty by the Narc government through ERSWEC (2003-2007) from the current estimated level of $56.7 \%$ to $51.8 \%$ by the year 2007 has been overshadowed and eclipsed with the politics of Anglo-Leasing corruption. The rapid economic growth assured of $7 \%$ through job creation and expansion of economic opportunities and resources for the poor has aggravated the hopes and expectations of the many leaving the aged, marginalized and economically disadvantaged communities at the grace of God and well-wishers. Furthermore, the resources of those who assist their aging parents are also dwindling due to divided responsibilities hence support to the elderly is highly limited.

\subsection{The Nutritional in-take of the elderly}

The findings indicated that the majority of the respondents' nutritional intake was poor (See table 6) due to limited resources. While an evaluation of nutritional status is difficult with all age groups and particularly so with the elderly, this study asserts that nutritional status, physical health and degenerative effects of the aging process are inter-related and therefore is not always possible to separate the influences of the inadequate nutrition from changes resulting from physiological aging and degenerative diseases.

On nutrition, the elderly hardly have enough to eat, as they are not physically able to farm and have limited sources for affording a good diet. Some elderly take a meal a day and are not keen on diet as some have limited knowledge, they lack the foods to buy or have no access and for those that can afford might lack someone to prepare the meal in the best way they would have liked. In Nyanza province, there are no Nursing Home facilities like those in developed nations where professionals can address the dietary interests of the elderly. Given the elderly are a highly vulnerable population, there needs to be an instituted policy to take care of the them either by training nutritionists health care gives or members of the family to provide the need nutritional care as none exists.

\subsection{The Health status of the elderly}

The findings of the study indicated that the majority of the respondents experienced varied health related problems with high blood pressure being the leading. Given the fact that most of the elderly do not go for regular check-ups, this complicates their health conditions and way of life. Besides, most government hospitals and clinics are a distance to access due to poor infrastructure and lack of a well-organized system that cares for the elderly. Furthermore, these health facilities are not well-equipped and lacked qualified staff to handle the sick.

According to Austin (1978), depression, tiredness, weight loss, or decreased appetite can have many causes and are not necessarily recognized as nutritional problems, particularly in the aged for whom such characteristics may erroneously be considered to represent normal aging. Nutritional deficiencies are difficult to diagnose and treat in that symptoms and cure are neither explicit nor finite. 
The government can make life comfortable for the senior citizens by improving infrastructure so that accessibility to the hospital or health clinics is possible. The government needs to ensure there is enough medicine, services given are quality and the residents have knowledge of the services available. This enlightenment can be programs on health matters through televisions, radio and posters.

\section{The coping mechanism}

The issue of housing for the elderly is a major concern yet there is no clearly enacted policy on the development of nursing homes or assisted living houses as it is in the developed countries. The existing private sector development of nursing homes is only starting in the urban centers where about two or so exist. The government has not come up with a policy regarding the establishment of affordable nursing home houses or living assisted houses for the elderly. Once established, the elderly will be centrally located whereby providing the necessary services will be easier and monitoring their health conditions will be an opportunity for the elderly to enjoy at their old age.

\subsection{Government policy on the elderly}

The policy framework in Kenya is not clear on how to maintain the challenges and declining economic growth, increased poverty, high unemployment and underemployment levels, insecurity, declining health standards and bad governance among the many vices facing the NARC government that came to power in December 2002. The long-term policy framework contained in the National Poverty Eradication plan (NPEP) 1999-2015 has not outlined anything specific on how to assist the elderly overcome their socio-economic woes. The economic performance of Kenya indicates that income per capita has declined from US dollars 271 in 1990 to 239 dollars in 2002. This persistent economic performance has aggravated the problem of poverty that is estimated at $56 \%$ and the most affected are the elderly over $60+$ whose economic power to purchase basics for their survival is greatly limited. The most affected are those in rural areas where accessibility to financial resources is very limited.

Secondly, the unemployment rates stagger at about $15 \%$ of the labour forces and the youths account for $45 \%$ of this total. The implication here is that the youth are not able to meet their basic needs, thus in an African society where the young depend on their parents, this has widened the gap of dependence ratio as the elderly are on the receiving side for they have to provide for their children. The elderly resources are stretched and as the case was in Nyanza province, $79.1 \%$ of the elderly could not manage to sustain this socio-economic burden, as their incomes were less than Kenya Shillings 4000/. There is need for the government to institute a clear policy on how to assist the elderly, either by offering some financial assistance, improving their social security benefits or subsidizing the prices of goods bought by the elderly by giving some social welfare cards for identification for the senior citizens.

Thirdly, the poverty reduction policies and programs by the Kenyan government aimed at improving economic growth and reducing poverty as detailed in the Sessional Papers, Development Plans, Social Dimensions of Development among others have not rejuvenated the Kenyan economy to the levels that the elderly could enjoy the benefits. Thus, being the highly vulnerable, the situation is of concern as bad governance, inefficient delivery of services, HIV/Aids pandemic, environmental factors and the adverse effects of structural adjustment programs have worsened the economic situation in Kenya and the elderly in the rural areas are no exception.

Last but not least, the Kenyan government policy on improving affordability, quality and access to basic health care and nutrition is another hard reality to come by in a society badly ridden by corruption scams and counter-accusations among the political circles of the government. Most health facilities in Kenya are under-staffed, that is, one doctor serving 3000 persons, whereas in some health centers or dispensary one can hardly find a clinical officer leave alone a nurse. There is a problem of lack of adequate facilities, medicine and basic amenities like water, theatre rooms, toilets, and surgical equipment among other things. The health facilities are inaccessible due to poor infrastructure in terms of roads, communication networks such as telephones to call for emergencies (even mobiles some areas have poor networks) and a place like Gusiiland with heavy rains, roads are impassable. In cases of emergencies, the elderly are not able to access the health facilities adequately. The agony of getting medical attention puts the elderly through difficulties, stress and unnecessary inconveniencies as expressed by the respondents. There are no established facilities to meet the needs of the poor who need highly specialized care. Consequently, there is need to develop a policy in regard to Medicare as it is in the developed countries where there are specialized vehicles for transporting the elderly and the disabled. In most cases the elderly go to hospital by public means, which is even painful and wanting for the elderly need to be comfortable at their later years. 


\section{Conclusions and recommendations}

While the elderly are highly vulnerable and yet have served the society during their youthful years, both the government and society have got to pay the power back by assisting the elderly to enjoy their lives in the after years. Ideally the policies instituted must meet the basic wants of those not able to support themselves both financially and materially at the time when they are not physically able to support themselves. Neither the government nor society may be able to avoid problems and challenges that face the elderly, but should certainly learn how to control the ever-existing socio-economic and political problems and challenges facing society today.

Wisdom has it that even developed nations strive to plan how to adequately provide to the elderly, but at least countries like USA, Britain, Canada among others have established elaborate systems and defined policies that guide these governments in taking care of the elderly from whom Kenya can borrow a leaf. In third world countries, manageable standards have not been achieved but there is need to establish policies regarding the provision of Medicare, housing or nursing homes and food supplements to the elderly. This direction is not clearly defined in Kenya, but can help focus on the welfare of the elderly if initiatives are taken now and not tomorrow.

This study makes the following recommendations based on its findings:

[a] As regards the socio-economic status of the elderly, there ought to be efforts to improve their living standards by subsidizing their incomes through improved pension schemes, subsidized prices for commodities and services for the elderly, that is, by issuing the elderly with senior citizen cards for identification.

[b] On nutritional in-take, it is to ensure that community social service sectors are strengthened and well equipped to identify and register senior citizens and provide the elderly with information on diet, preparation and recommended servings.

[c] In the case of health status, there is need to create a conducive environment that is stress tolerant, that is, fewer problems, breathing space, caring and assistance to the elderly. Provide affordable and accessible medical care and services. There should be access to information for preventative care.

[d] On the issue of coping mechanisms, there is need for decent housing for the elderly to ease problems of staying alone, with family members or burdening the surrounding community. Also, the elderly should not be overburdened by the responsibilities of caring for orphans, grandchildren or relatives.

[e] On the issue of policy regarding the elderly,

[i] The government of Kenya should create a policy to subside the medical care services and foodstuffs for the elderly, so as to ensure their nutritional and health conditions are safely catered for at all times.

[ii] The government of Kenya needs to establish a policy on nursing homes of decent housing for the elderly so that it can ease the problem of relying on family members, friends or organizations for support or alternate care.

[iii] The government of Kenya needs to establish a policy on dependence by the orphans occasioned by HIV/Aids or extended family members on the elderly. Due to increased social problems, unemployment or the young people going to work for long hours, grandparents are left to take care of the young ones or orphaned children.

[iv] Finally, the government of Kenya needs to create a policy that will allow investors to establish day cares for young children or homes for orphaned children so as to easy the burden put on the elderly in taking care of the young ones. The elderly need time for themselves and only a few hours of company from the grandchildren. In some cases the elderly have been allowed to look for food to feed these children, shoulder their medical care among other things.

\section{References}

Ainlay, S. C. \& Smith, D.R. (1984). Aging and Religious participation. Journal of Gerontology, 39, 357-63.

Alder, N.E., Boyce, T., Chesney, M.A., Cohen, S., Folkman, S., Kahn, R.L. \& Syme, S. L. (1994). Socioeconomic status and health. The challenge of the gradient. American Psychologist, 49, 15-24. http://dx.doi.org/10.1037/0003-066X.49.1.15

Antonucci, T. C. (1991). Attachment, social support, and coping with negative life events in mature adulthood. (eds.), Life-span development developmental psychology. Perspectives on stress and coping (pp. 261-76). Hillsdale, NJ: Erl-baum.

Beeuwkes, A. (1960). Studying the food habits of the elderly. J. Am. Diet Assoc., 37. 215. 
Boss'e, R., Aldwin, C.M., Levenson., M.R. \& Workman-Daniels, K. (1991). How Stressful is retirement? Findings from the normative aging study. Journal of Gerontology: Psychological Sciences, 46, pg 9-14.

Boykin, L. S. (1980). Problems of the older person in obtaining adequate nutrition. Aging, No. 311-312, 4, Sept.Oct..

Busch, C. M., Zonderman, A. B. \& Costa, P. T., Jr. (1994). Menopausal tradition and psychological distress in a nationally representative sample: Is menopause associated with psychological distress? Journal of Aging and Health, 6, 209-28. http://dx.doi.org/10.1177/089826439400600205

Cicirelli, V.G. (1983). Adult children and their elderly parents. In T. H. Brubaker (Ed.) Family relationships in later life (PP. 31-46). Baverly Hills, CA. Sage.

Crimmins, E. M. \& Ingegneri, D. G. (1990). Interaction and living arrangements of older parents and their children. Research on Aging, 12, 3-35. http://dx.doi.org/10.1177/0164027590121001

Cutler, S.J. \& Grams, A. E. (1988). Correlates of self-Reported everyday memory problems. Journal of Gerontology: Social Sciences, 43, S82-90.

Cutler, W. B. \& Garcia, C. (1993). Menopause: A guide for Women and those who love them. New York: Norton.

Kenya Country Report of 2003. Economic Recovery Strategy for Wealth and Employment Creation (ERSWEC) 2003-2007.

Millennium Development Goals (MDGS) 2001-2015.

National Development plan 2002-2008. Effective Management for sustainable economic growth and poverty Reduction.

National Poverty Eradication Plan (NPEP) 1999-2015.

Nizel, A.E. (1976). Role of Nutrition in the oral health of the aging patient. Dent, Clin. North AM, 20:569.

Ondigi, A. N. (2003). Factors influencing prenatal health Status among expectant Women in low income areas of Nairobi. Kenya, KU catalog publications.

Siegel, J. S. (1976). Prospective trends in the size and structure of the elderly population, Impact of mortality trends and some implications. Current Population Reports, Special studies series, p-23, No. 78, Washington, D.C. (1979). U.S. Bureau of Census.

The Poverty Reduction Strategy paper (PRSP) 2001-2010.

United Nations Department of Economic and Social Affairs. (UNDESA 2010).

United Nations Development report - International Poverty Centre. (2006).

Table 1. Showing alternative coping mechanisms

\begin{tabular}{|l|c|c|}
\hline Coping Mechanisms & Frequency & Percentage \\
\hline Self motivation & 29 & 24.1 \\
\hline Engage in religion & 45 & 37.1 \\
\hline Despair & 15 & 10.0 \\
\hline Socialization with friends & 31 & 25.8 \\
\hline
\end{tabular}

Table 2. Frequency table showing the respondents' dietary intake

\begin{tabular}{lcccccccc}
\hline Description & $\begin{array}{l}\mathbf{1 - 2} \text { times a week or } \\
\text { less }\end{array}$ & $\begin{array}{l}\mathbf{3 - 4} \text { times } \\
\text { week }\end{array}$ & $\begin{array}{l}\text { Usually once } \\
\text { day }\end{array}$ & $\begin{array}{l}\text { 2 or more } \\
\text { times } \\
\text { day }\end{array}$ & $\begin{array}{l}\text { Do } \\
\text { use }\end{array}$ \\
\hline Food & $\%$ & $\%$ & & & $\%$ & $\%$ \\
groups & & & & & & \\
A - group & 33.0 & & 19.0 & 29.0 & 13.0 & 6.0 \\
Meat & 37.0 & 12.0 & 11.0 & 5.0 & 35.0 \\
Fish & 32.0 & 21.0 & 15.0 & 10.0 & 22.0 \\
Eggs & 42.0 & 24.0 & 17.0 & 11.0 & 7.0 \\
Beans & & & & & & & \\
\end{tabular}




\begin{tabular}{lccccc} 
Chicken & 57.0 & 15.0 & 4.0 & 2.0 & 22.0 \\
B - group & & & & & \\
Cheese & 17.0 & 7.0 & 5.0 & 3.0 & 66.0 \\
Milk & 11.0 & 9.0 & 47.0 & 24.0 & 9.0 \\
Yogurt & 19.0 & 7.0 & 5.0 & 1.0 & 68.0 \\
Ice-cream & 19.0 & 3.0 & 9.0 & 1.0 & 67.0 \\
C - group & & & & & \\
Fruit & 4.0 & 11.0 & 49.0 & 37.0 & 3.0 \\
Vegetables & 7.0 & & 39.0 & 39.0 & 3.0 \\
D - group & & 18.0 & & & \\
Whole grain & 22.0 & 14.0 & 25.0 & 20.0 & 15.0 \\
Cereals & 21.0 & 12.0 & 29.0 & 21.0 & 15.0 \\
Bread & 8.0 & & 44.0 & 30.0 & 7.0 \\
\hline
\end{tabular}

Multiple responses

Table 3. Showing the Elderly health related Problems

\begin{tabular}{|l|c|c|}
\hline Disease & Frequency & Percentage \\
\hline High blood pressure & 80 & 66.6 \\
\hline Diabetes & 16 & 13 \\
\hline Joint aches & 73 & 60.8 \\
\hline Menopause related discomforts & 14 & 17.5 \\
\hline Suffered from HIV/Aids & 18 & 22.0 \\
\hline Affected by HIV/Aids & 24 & 29.0 \\
\hline Prostate problems & 23 & 19.2 \\
\hline
\end{tabular}

$\mathrm{N}=120$ multi-response

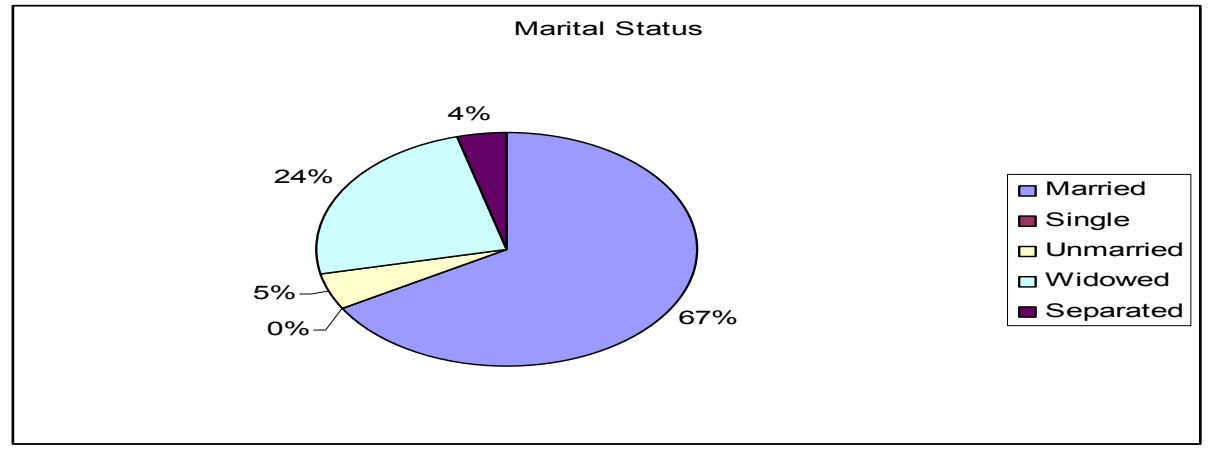

Figure 1. Showing the respondent's marital status

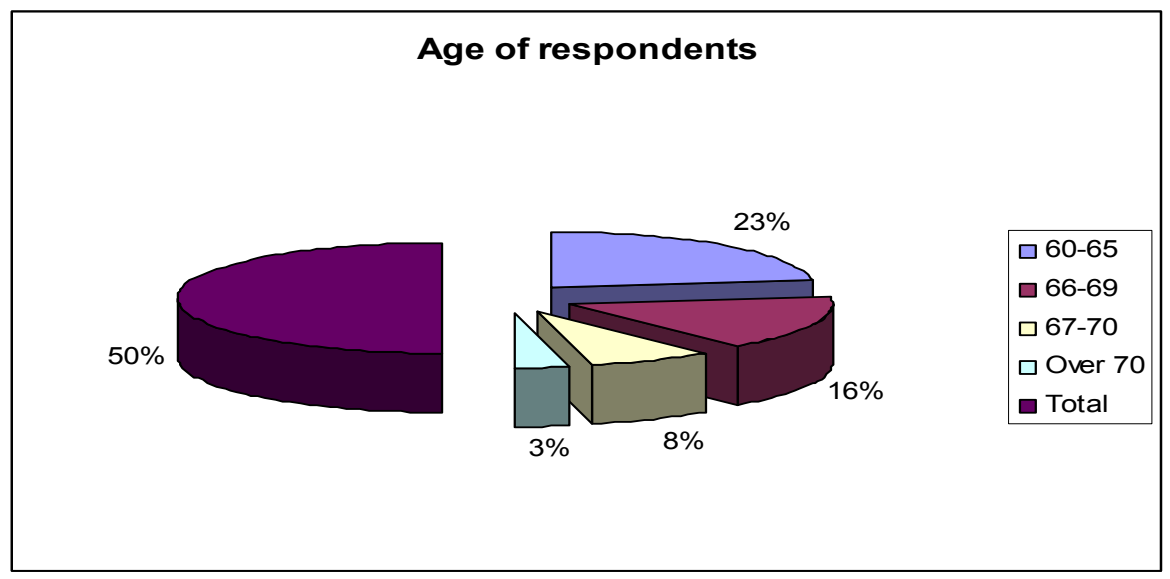

Figure 2. Showing the respondent's age distribution 


\section{Employement status}
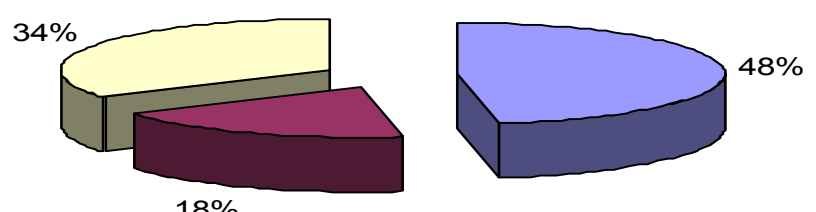

$\square$ Unemployed

$\square$ On contract

$\square$ Self-employed

$18 \%$

Figure 3. Showing the respondent's employment status

\section{Level of income}

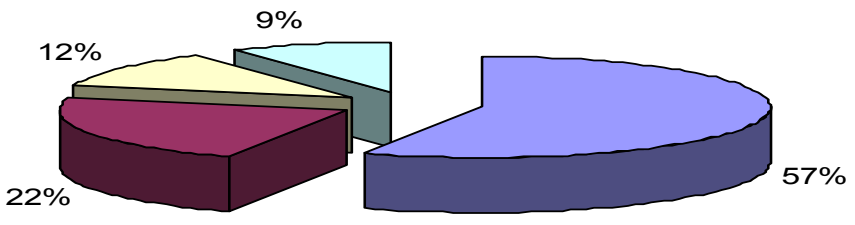

ㅁ $0-2000$

口 2100-4000

4100-6000

$\square$ Over 6000

Figure 4. Showing the respondent's range of monthly income

\section{Food group Intake}

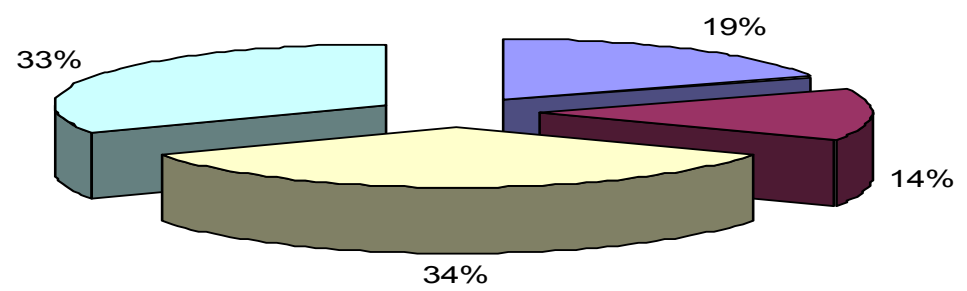

$\square \mathrm{A}$

$\square B$

$\square \mathrm{C}$

$\square \mathrm{D}$

Figure 5. Showing a summary of the Food -intake 